Keywords: P300; Taql-A1; Alcoholism; Event-related potentials; Abstinence; Endophenotype.

\title{
P300 in alcohol dependence: Effects of TaqI-A genotype
}

\author{
M.A. Jiménez-Arriero* \\ J. Rodríguez-Torresano* \\ G. Ponce* \\ J. Hoenicka* \\ R. Rodríguez ${ }^{*}$ \\ G. Rubio* \\ T. Palomo*
}

* Department of Psychiatry, Hospital 12 de Octubre, Madrid

SPAIN

\begin{abstract}
Background and Objectives: TaqI-A polymorphism, related to D2 dopamine receptor (DRD2), and event-related P300 potentials have been considered markers of alcohol dependence. The effect of alcohol use variables and TaqI-A on P300 in a single sample have been hardly analysed previously. This study examined changes in P300 parameters after six months of abstinence in alcohol-dependent subjects classified by their TaqI-A genotype.

Methods: 102 men with alcohol dependence were studied at baseline and at 6 months of continued abstinence. P300 was recorded using an auditory paradigm. TaqI-A polymorphism was genotyped: $34.3 \%$ of sample was classified as A1[TaqI-A1/TaqI-A1and TaqI-A1/TaqI-A2] and $65.7 \%$ as A2 [TaqI-A2/TaqI-A2]. The association between P300 and TaqI-A and the correlation with age and alcohol consumption were considered.

Results: The abstinence period was not associated to differences in neither P300 latency $(\mathrm{F}[1,99]=1.154 \mathrm{p}=0.285)$ nor amplitude $(\mathrm{F}[1,99]=1.453, \mathrm{p}=0.231)$. A1 subgroup was related to a longer latency $(\mathrm{F}[1,99]=5.055 \mathrm{p}=0.027)$, an early abuse age onset $(\mathrm{F}[1,100]=$ $14.552 \mathrm{p}<0.001)$ and close to be significant to an early dependence age onset $(\mathrm{F}[1,100]=$ $3.868 \mathrm{p}=0.052$ ). Other drinking pattern variables were not associated to p300 measures. Family history for alcoholism and TaqI-A were not related $(\mathrm{X}[1]=0.327 \mathrm{p}=0.568)$ and no association was found with p300 measures. Current age correlated positively with P300 latency (F[1, $99]=26.082, \mathrm{p}<0,001)$ and negatively with amplitude $(\mathrm{F}[1,99]=5.297 \mathrm{p}=0.023)$. P300 amplitude was not influenced by alcohol use variables nor TaqI-A polymorphism.

Conclusions: P300 latency could be a biological marker of vulnerability to alcohol dependence related to TaqI-A1 polymorphism, irrespective of alcohol use variables.
\end{abstract}

Received: 11 November 2008

Revised: 10 August 2009

Accepted: 14 September 2009 


\section{Background and Objectives}

P300 is a positive electrical deflection recorded at maximal amplitudes over the midline centroparietal scalp in response to rare attended events within a sequence of similar, but discriminate, stimuli. Although the functional significance of P300 is still debated $^{1,2}$, its amplitude indexes the allocation of resources for the evaluation of stimuli and its sensitivity to instrumental manipulation indicates that it reflects a neural substrate of controlled information processing strategies ${ }^{3}$.

Reduced P300 amplitude has been reported in many psychiatric disorders, including schizophrenia $^{4}$, depression ${ }^{5}$, and alcoholism ${ }^{6}$. Various studies have related the presence of lower P300 amplitude or longer P300 latency with alcoholism ${ }^{7-10}$. Many of these studies have been carried out on children of alcoholics, so P300 alterations have been considered a genetic marker of vulnerability to alcoholism ${ }^{11}$ or an endophenotype of an alcoholism subtype ${ }^{12-15}$.

The brain dopaminergic system, which is centrally involved in reward and learning, has been widely studied in substance use disorders. The TaqI-A single-nucleotide polymorphism (SNP) (rs1800497) located near the 3 'region of the dopamine D2 receptor gene (DRD2; chromosome 11q22-q23) has been considered a genetic marker of alcoholism ${ }^{16-}$ 19. TaqI-A SNP consists of the substitution of $\mathrm{C}>\mathrm{T}$, also called the A2 and A1 alleles, respectively, which affects a previously unidentified protein kinase gene called ANKK1 (ankyrin repeat and kinase domain containing 1$)^{20}$. There is no consensus about the role of the A1 allele and A1 genotype (heterozygous or homozygous for A1 allele) in addictive behaviour, but three meta-analyses have shown a robust association between TaqI-A SNP and alcoholism ${ }^{21,22}$.

In addition, the P300 wave has been associated with dopaminergic activity ${ }^{23}$ and TaqI-A polymorphism has been associated with P300-wave changes.

The relationship between P300 wave and TaqI-A has been examined in non alcoholic sons of alcoholics. Longer latencies ${ }^{24}$ and amplitude attenuation have been observed in A1 subjects ${ }^{25,26}$. We found that A1 alcohol-dependent males had longer P300 latencies than A2 alcohol dependents and healthy controls $^{27}$.

Nonetheless, other studies have not found any differences between the A1 and A 2 subgroups $^{28}$.

To further examine P300 capability to measure possible differences associated to the TaqI A1 and A2 subgroups and to ethanol toxic effect in alcohol dependence, we studied changes in the P300 wave after a period of abstinence in a sample of alcohol-dependent males classified by TaqI-A genotype. There have been published several works that had taken into account an abstinency period and the influence of family history for alcoholism on P300wave measures but not the TaqI A polymorphism ${ }^{29-32}$.

\section{Methods}

This longitudinal study compared P300 amplitude and latency in a group of patients with alcohol dependence at two different times: (T1) baseline (after the detoxification period) and (T2) after six months of abstinence from alcohol. The sample was classified according to the presence or absence of TaqI-A1. 


\section{Study population}

Our sample consisted of 115 adult males with alcohol dependence consecutively recruited in the Alcoholism programme of Hospital Universitario 12 de Octubre, of Madrid, Spain. The recruitment period included 66 days. Thirteen subjects relapsed in the 6 months after detoxification, so the group finally included had 102 patients. Sample demographic and clinical variables are summarised in Table 1.

The inclusion criteria were male patients, age range 18 to 65 years, who met DSM-IV criteria for alcohol dependence and had completed a detoxification period (at least 3 weeks), and who signed a written informed consent form. The exclusion criteria were the presence of other associated DSM-IV axis I psychiatric diagnoses, current neurologic disorder, auditory deficit, serious or chronic somatic illness unrelated to alcoholism and requiring treatment, presence of consanguinity or ancestors in the three previous generations that could cause genetic stratification. Alcohol abstinence was measured by patient self-reports, information gathered from families, ALT (alanine aminotransferase), AST (aspartate aminotransferase) and gammaglutamyl-transpeptidase (GGT) values.

\section{Instruments}

A semi-structured interview was used to collect sociodemographic data. The Structured Clinical Interview (SCID) ${ }^{33}$ from the Diagnostic and Statistical Manual of Mental Disorders, 4th edition (DSM-IV) was used to diagnose substance abuse or dependence. The Severity of Alcohol Dependence Scale (SADS) was also used.

Information about family history of alcoholism was collected by interviewing first-degree relatives. The subject was considered to have positive family antecedents of alcoholism if there was a first-degree relative with a history of alcohol dependence. When it was not possible to interview relatives the diagnosis was made by applying the Research Diagnostic Criteria-Family History (RDC-FH).

\section{Genotyping}

Genotyping was performed using a polymerase chain reaction (PCR), as described elsewhere ${ }^{34}$. Twenty microlitres of the PCR product were digested with 2 units of TaqI restriction enzyme (Boehringer Mannheim) for 4 hours at $65^{\circ} \mathrm{C}$. The resulting fragments were 310,185 and $125 \mathrm{bp}$ for the A2/A1 genotype, 185 and $125 \mathrm{bp}$ for the A1/A1 genotype and 310 bp for the A2/A2 genotype. Patients were grouped according to the presence of the TaqI-A1 allele $(\mathrm{n}=35, \mathrm{~A} 1(+)$ : genotypes TaqI-A1/TaqI-A1 and TaqI-A1/TaqI-A2) or absence of the TaqI-A1 allele $(\mathrm{n}=67, \mathrm{~A} 2$ : genotypeTaqI-A2/TaqI-A2).

\section{Electrophysiologic recording and event-related potentials}

The P300 study was carried out in the Event-Related Potentials (ERP) Unit of Hospital Universitario 12 de Octubre after verifying the absence of any auditory deficit in patients by tonal audiometry. A $M E D$ ELEC brand Sapphire model ERP device, type 2, was used. The bioelectric cerebral activity of long latency was registered after an unexpected and infrequent stimulation (odd-ball). The stimulation was a highpitched $(2000 \mathrm{~Hz}, 70 \mathrm{~dB})$ aleatory target sound with a presence of $10 \%$ in a sequence of regular sounds $(1000 \mathrm{~Hz}, 70 \mathrm{~dB})$. Time interstimuli was $2 \mathrm{sec}$ for regular sound. Both regular and randomised sounds had a duration of $100 \mathrm{~ms}$. 

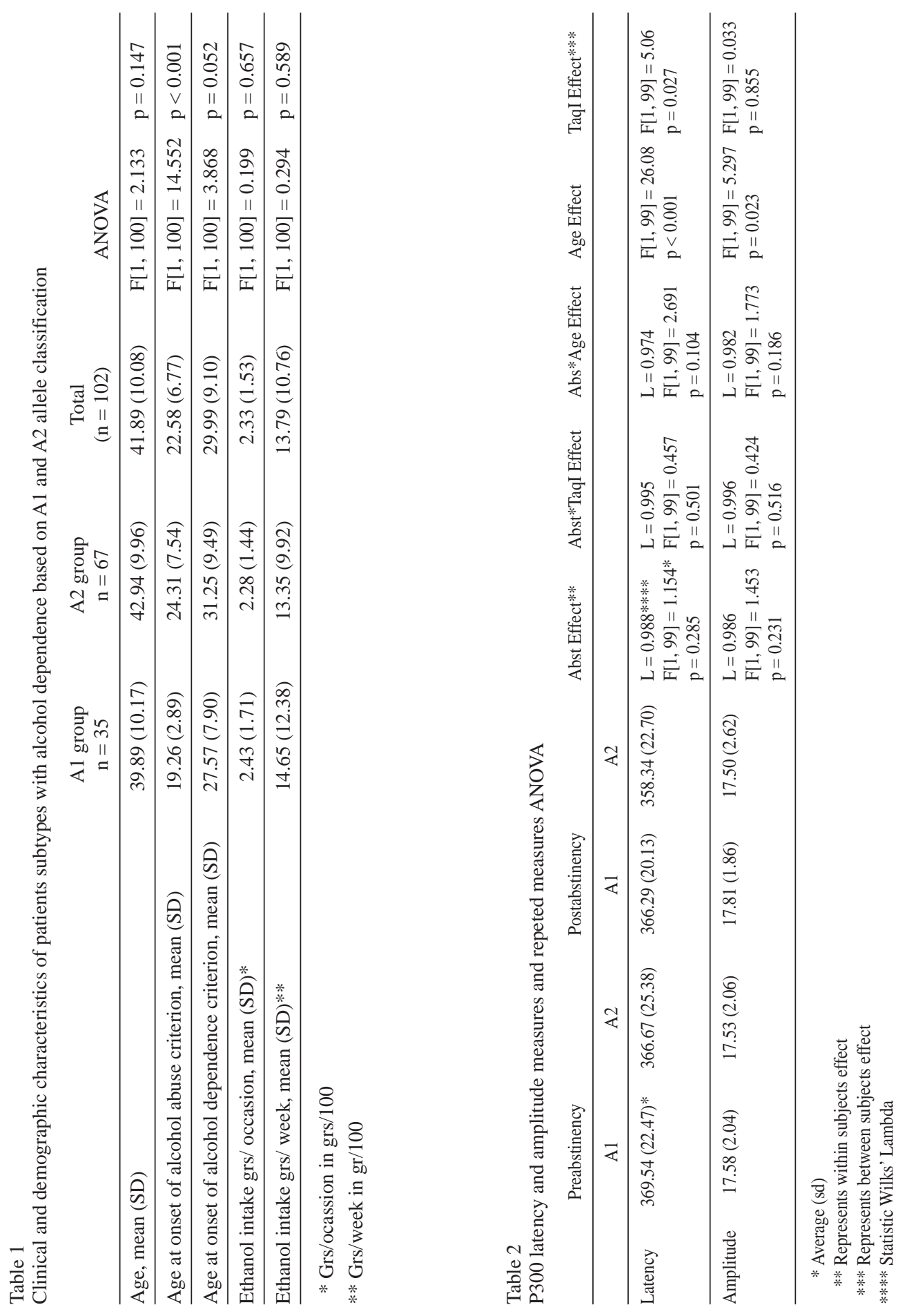
During the test, the patient was asked to remember the number of infrequent (1000 $\mathrm{Hz}$ ) stimuli. The EEG was recorded at parietal $(\mathrm{Pz})$ scalp location because of the highest amplitude distributed ${ }^{35}$.

The reference electrode was placed on the nose tip, and the ground electrode on the forehead. The high-pass filter was $0,1 \mathrm{~Hz}$ and the low-pass, $30 \mathrm{~Hz}$. The epochs were recorded from $100 \mathrm{~ms}$ prestimuli to $800 \mathrm{~ms}$ later. Any epochs with voltage above 70 were considered artifacts and rejected.

\section{Statistical analysis}

Analysis of variance has been used to test quantitative variables between TaqI-A subgroups (A1 vs. A2). Possible association between TaqI-A and family history for alcoholism were tested with Chi-square.

Differences between P300 variables at preabstinency versus postabstinency have been analysed using a repeated measures ANOVA. We have considered the abstinency period like within subject effect and TaqI-A like between subjects effect. Possible covariates were studied in the ANOVA.

The SPSS statistical package version 12 was used for analysis.

The Hardy-Weinberg equilibrium was satisfied in our sample $(\mathrm{c} 2=0.24, \mathrm{df}=1, \mathrm{p}=$ $0.62)$.

\section{Results}

The A1 subgroup $(\mathrm{n}=35,34.3 \%)$ had an age average of $39.89(\mathrm{sd}=10.17)$ years, while it was $42.94(\mathrm{sd}=9.96)$ for A2 subgroup $(n=67,65.7 \%)$. A1 was related to a more severe drinking pattern, like an earlier abuse age onset $[\mathrm{F}[1,100]=14.552 \mathrm{p}<0.001]$ and almost significantly to an earlier dependence age onset $(F[1,100]=3.868 \mathrm{p}=0.052]$. Interestingly family history for alcoholism was not related neither to TaqI-A (X[1] = $0.327 \mathrm{p}=0.568$ ) neither to alcohol dependence characteristics.

Regarding age and drinking pattern characteristics (see table 1), there were not differences between 102 and 115 patients sample.

The effect of the abstinence period on this alcoholic patients sample has not generate significant differences on neither p300 wave latency $(\mathrm{L}=0.988 \mathrm{~F}[1,99]=1.154 \mathrm{p}=0.285)$ nor the amplitude $(\mathrm{L}=0.986 \mathrm{~F}[1,99]=1.453$, $\mathrm{p}=0.231$ ). However TaqI-A effect was statistically significant on latency. Hence, A1 subgroup showed higher latency values than A2 subgroup $[F[1,99]=5.055 \mathrm{p}=0.027]$. Amplitude results were irrespective of TaqI-A.

Age influenced in a significant manner to both latency and amplitude. Patients with a higher age have a longer latency $(\mathrm{F}[1,99]=$ $26.082 \mathrm{p}<0.001)$ and a minor amplitude $(F[1,99]=5.297 p=0.023)$. None of the rest of variables were statistically significant.

\section{Discussion}

Our study supports that P300 wave measures are not influenced by a six months abstinence period. Others published works have offered similar data ${ }^{30-32}$. It is interesting that these authors arrive to the same conclusion from works methodologically different and taking into account very different sobriety length periods.

Chronic alcohol intake have been extensively associated to P300 amplitude reduction. However we did not find any correla- 
tion between the amount of alcohol intake in the previous drinking period and changes in either P300 amplitude or latency, similar to other published results ${ }^{31}$. A possible explanation for this could be the presence of an idiosyncratic vulnerability to the ethanol, what has been sustained by some authors ${ }^{36}$. In other words, once subjects reach a certain level of alcohol intake, P300 values may not modify in a significant manner with a higher consumption what may obscure the association. Another possible explanation of the absence of correlation may be the presence of different metabolisation rates.

The absence of changes in P300 measures after an abstinence period and its lack of association with alcohol intake amount and with time consumption suggest a minor roll of the toxic effect in the alcohol dependence, idea sustained for different authors ${ }^{16,22}$. An alternative explanation could be that chronic alcohol intake has a not reversible effect on P300 measures ${ }^{31}$.

The association between TaqI-A polymorphism and P300 wave measures had been studied by several authors, mainly in non alcoholic young population. Considering that P300 performance has been associated to disrupted sensory gating 37,38 and to dopamine dysfunction ${ }^{39,40}$, it could be hypothesised that TaqI-A is involved in dopamine disorders underlying P300 neurophysiologic substrates. It is congruent with it that the A1 genotype had been related to a hipodopaminergic state, with a reduced number of DRD2 in striatum ${ }^{41}$. Hence, dopamine dysfunction could contribute both to P300 wave changes and to a dysfunctional reward system. An earlier alcohol abuse age and others manifestations of a more severe alcoholism have been hypothesised to be consequences of $\mathrm{it}^{42}$.
In this sample, TaqI-A1 subgroup is associated to a P300 longer latency, to an earlier alcohol abuse age onset and is very close to reach a statistic significant association with alcohol dependence age onset. It is similar to data from other studies ${ }^{27,42}$ and supports the presence of a genetic effect on alcoholism severity. Interestingly our study results show that family history for alcoholism is not related to neither TaqI-A polymorphism nor P300 measures nor drinking pattern variables. There are some published works that are congruent with this ${ }^{43-45}$ and others that suggest a positive association among these variables ${ }^{42,} 46,47$. Possibly there are different genotypes not sufficiently represented in the sample that could be related to different metabolitation rates. The absence of differences in P300 amplitude related to DRD2 genotype in our study may be due to this reason or even to the absence of a genetic effect.

On the other hand, our results also showed that the association between the TaqI-A genotype and P300 measures might be obscured if the age effect is not controlled. Age effect is observed in young people and adults $^{25}$, which suggests that must be controlled statistically even if the sample contains young people. It is important to note that some studies have included young people in the belief that age effect on P300 values is unappreciable in people under 50 years old ${ }^{48}$. It has been published that differences on P300 amplitude from alcoholic descendant adolescents respect controls tend to reduce with age. The high average age in our sample could have contributed to reduce the genetic effect on P300 values associated to TaqI-A.

In summary, our results suggest that P300 event related potentials are an useful instrument to detect the genetic effect associated to TaqI-A polymorphism. Latency could be 
related to fact of alcohol consumption (possibly not to intake amount), inheritance, and age. They support the hypothesis that this association is related to the function of the brain dopaminergic circuit.

The fact that the sample was small and did not include women are limitations of our study. A sample with a lower average age could reveal more marked differences in P300-wave latency between A1 and A2 subgroups. More studies are needed to clarify the influence of genetic factors, age and alcohol intake on P300-wave changes.

\section{References}

1. Soltani M, Knight RT. Neural origins of the P300. Crit Rev Neurobiol 2000; 14(34): 199-224.

2. Sambeth A, Maes JH, Brankack J. With long intervals, inter-stimulus intervals is the critical determinant of the human P300 amplitude. Neurosci Lett 2004; 359(3): 143-146.

3. Prinzel LJ 3rd, Freeman FG, Scerbo MW, Mikulka PJ, Pope AT. Effects of a psychophysiological system for adaptive automation on performance, workload, and the event-related potential P300 component. Hum Factors 2003; 45(4): 601-613.

4. Bramon E, Rabe-Hesketh S, Sham P, Murray RM, Frangou S. Meta-analysis of the P300 and P50 waveforms in schizophrenia. Schizophr Res 2004; 70(2-3): 315-329.

5. Anderer P, Saletu B, Semlitsch HV, Pascual-Marqui RD. Structural and energetic processes related to P300: LORETA findings in depression and effects of antidepressant drugs. Methods Find Exp Clin Pharmacol 2002; 24: 85-91.

6. Begleiter H, Porjesz B. Neurophysiological phenotypic factors in the development of alcoholism. In: Begleiter H, and Kissin B, editors. The Genetics of Alcoholism. NewYork: Oxford University; 1995. p. 269-293.

7. Polich J, Bloom FE. P300 and alcohol consumption in normals and individuals at risk for alcoholism. A preliminary report. Prog Neuropsychopharmacol Biol Psychiatry 1986; 10(2): 201-210.

8. Cohen HL, Wang W, Porjesz B, Begleiter H. Auditory $\mathrm{P} 300$ in young alcoholics: regional response characteristics. Alcohol Clin Exp Res1995; 19(2): 469-475.
9. Nacher V. Genetic association between the reduced amplitude of the P300 and the allele A1 of the gene which codifies the D2 dopamine receptor (DRD2) as possible biological markers for alcoholism. Rev Neurol 2000; 30(8): 756-763.

10. Polich J, Ochoa CJ. Alcoholism risk, tobacco smoking, and P300 event-related potential. Clin Neurophysiol 2004; 115(6): 1374-1383.

11. Enoch MA, White KV, Harris CR, Rohrbaugh JW, Goldman D. The relationship between two intermediate phenotypes for alcoholism: low voltage alpha EEG and low P300 ERP amplitude. J Stud Alcohol 2002; 63(5): 509-517.

12. Cohen HL, Porjesz B, Begleiter H, Wang W. Neuroelectric correlates of response production and inhibition in individuals at risk to develop alcoholism. Biol Psychiatry 1997; 42(1): 57-67.

13. Cohen HL, Porjesz B, Stimus AT, Begleiter H. Effects of ethanol on temporal recovery of auditory-evoked potentials in individuals at risk for alcoholism. Alcohol Clin Exp Res 1998; 22(4): 945-953.

14. Berman SM, Noble EP. Reduced visuospatial performance in children with the D2 dopamine receptor A1 allele. Behav Genet 1995; 25(1): 45-58.

15. Hesselbrock V, Begleiter H, Porjesz B, O’Connor S, Bauer L. P300 event-related potential amplitude as an endophenotype of alcoholism-evidence from the collaborative study on the genetics of alcoholism. J Biomed Sci 2001; 8(1): 77-82.

16. Blum K, Noble EP, Sheridan PJ, Montgomery A, Ritchie T, Jagadeeswaran P, et al. Allelic association of human dopamine D2 receptor gene in alcoholism. JAMA 1990; 263(15): 2055-2060.

17. Noble EP. D2 dopamine receptor gene in psychiatric and neurologic disorders and its phenotypes. Am J Med Genet B Neuropsychiatr Genet 2003; 116B(1): 103-125.

18. Noble EP, Blum K, Khalsa ME, Ritchie T, Montgomery A, Wood RC, et al. Allelic association of the D2 dopamine receptor gene with cocaine dependence. Drug Alcohol Depend 1993; 33(3): 271-285. Erratum in: Drug Alcohol Depend 1993; 34(1): 83-84.

19. Persico AM, Bird G, Gabbay FH, Uhl GR. D2 dopamine receptor gene TaqI A1 and B1 restriction fragment length polymorphisms: enhanced frequencies in psychostimulant-preferring polysubstance abusers. Biol Psychiatry 1996; 40(8): 776-784.

20. Neville MJ, Johnstone EC, Walton RT. Identification and characterization of ANKK1: a novel kinase gene closely linked to DRD2 on chromosome band 11q23.1. Hum Mutat 2004; 23(6): 540-545. 
21. Li MD, Ma JZ, Beuten J. Progress in searching for susceptibility loci and genes for smoking-related behaviour. Clin Genet 2004; 66(5): 382-392.

22. Noble EP. D2 dopamine receptor gene in psychiatric and neurologic disorders and its phenotypes. Am J Med Genet B Neuropsychiatr Genet 2003; 116B(1): 103-125.

23. Wang L, Kuroiwa Y, Li M, Kamitani T, Wang J, Takahashi T, et al. The correlation between P300 alterations and regional cerebral blood flow in non-demented Parkinson's disease. Neurosci Lett 2000; 282(3): 133-136.

24. Noble EP, Berman SM, Ozkaragoz TZ, Ritchie T. Prolonged P300 latency in children with the D2 dopamine receptor A1 allele. Am J Hum Genet 1994; 54(4): 658-668.

25. Berman SM, Noble EP, Antolin T, Sheen C, Conner BT, Ritchie T. P300 development during adolescence: effects of DRD2 genotype. Clin Neurophysiol 2006; 117(3): 649-659.

26. Hill SY, Locke J, Zezza N, Kaplan B, Neiswanger $\mathrm{K}$, Steinhauer SR, et al. Genetic association between reduced P300 amplitude and the DRD2 dopamine receptor A1 allele in children at high risk for alcoholism. Biol Psychiatry $1998 ; 43(1)$ : 40-51.

27. Jiménez-Arriero M.A., Ponce G., Rodríguez-Jiménez R, et al. TaqI-A polymorphism linked to the DRD2 gene and P300 in alcoholic patients. Eur J Psychiat 2006; 20(1): 45-53.

28. Ratsma JE, van der Stelt O, Schoffelmeer AN, Westerveld And A, Boudewijn Gunning W. P3 event-related potential, dopamine D2 receptor A1 allele, and sensationseeking in adult children of alcoholics. Alcohol Clin Exp Res 2001; 25(7): 960-967.

29. Keenan JP, Freeman PR, Harrell R. The effects of family history, sobriety length, and drinking history in younger alcoholics on P300 auditory-evoked potentials. Alcohol Alcohol 1997; 32(3): 233-239.

30. Glenn S, Parsons OA, Sinha R. Assessment of recovery of electrophysiological and neuropsychological functions in chronic alcoholics. Biol Psychiatry 1994; 36(7): 443-452.

31. Fein G, Chang M. Visual P300s in long-term abstinent chronic alcoholics. Alcohol Clin Exp Res 2006; 30(12): 2000-2007.

32. Porjesz B, Begleiter H. Human brain electrophysiology and alcoholism. In: Tarter R, Van Thiel D, editors. Alcohol and the Brain. New York: Plenum Press; 1985. p. 139-182.

33. First MB, Spitzer RL, Williams JB, Gibbon M. Entrevista estructurada para el DSM-IV (r) SCID-I. Barcelona: Masson; 1999.
34. Noble EP, Noble RE, Ritchie T, Syndulko K, Bohlman MC, Noble LA. D2 dopamine receptor gene and obesity. Int J Eat Disord 1994; 15(3): 205-217.

35. Chen TJ, Yu YW, Chen JY, Wang YC, Chen MC, Hong CJ. Association analysis of two dopamine D2 receptor gene polymorphisms and p300 event-related potential in depressive patients. Neuropsychobiology 2002; 46(3): 141-144.

36. Rodríguez Holguín S, Corral M, Cadaveira F. Visual and auditory event-related potentials in young children of alcoholics from high- and low-density families. Alcohol Clin Exp Res 1998; 22(1): 87-96.

37. Stojanov W, Karayanidis F, Johnston P, Bailey A, Carr V, Schall U. Disrupted sensory gating in pathological gambling. Biol Psychiatry 2003; 54(4): 474-484.

38. Berman SM, Ozkaragoz T, Noble EP, Antolin T, Sheen C, Siddarth P, et al. Differential associations of sex and D2 dopamine receptor (DRD2) genotype with negative affect and other substance abuse risk markers in children of alcoholics. Alcohol 2003; 30(3): 201-210.

39. Gallinat J, Bajbouj M, Sander T, Schlattmann P, Xu K, Ferro EF, et al. Association of the G1947A COMT (Val(108/158)Met) gene polymorphism with prefrontal P300 during information processing. Biol Psychiatry 2003; 54(1): 40-48.

40. Mulert C, Juckel G, Giegling I, Pogarell O, Leicht G, Karch S, et al. A Ser9Gly polymorphism in the dopamine D3 receptor gene (DRD3) and event-related P300 potentials. Neuropsychopharmacology 2006; 31(6): 1335-1344.

41. Noble EP, Blum K, Ritchie T, Montgomery A, Sheridan PJ. Allelic association of the D2 dopamine receptor gene with receptor-binding characteristics in alcoholism. Arch Gen Psychiatry 1991; 48(7): 648-654.

42. Ponce G, Jimenez-Arriero MA, Rubio G, Hoenicka J, Ampuero I, Ramos JA, et al. The A1 allele of the DRD2 gene (TaqI A polymorphisms) is associated with antisocial personality in a sample of alcohol-dependent patients. Eur Psychiatry 2003; 18(7): 356-360.

43. Bauer LO, O'Connor S, Hesselbrock VM. Frontal P300 decrements in antisocial personality disorder. Alcohol Clin Exp Res 1994; 18(6): 1300-1305.

44. Parsons OA, Sinha R, Williams HL.Relationships between neuropsychological test performance and eventrelated potentials in alcoholic and nonalcoholic samples. Alcohol Clin Exp Res 1990; 14(5): 746-755.

45. Polich J, Bloom FE. P300 from normals and adult children of alcoholics. Alcohol 1987; 4(4): 301-305. 
46. Cadoret RJ, Troughton E, O'Gorman TW, Heywood E. An adoption study of genetic and environmental factors in drug abuse. Arch Gen Psychiatry 1986; 43(12): 1131-1136.

47. Cadoret RJ, Yates WR, Troughton E, Woodworth G, Stewart MA. Adoption study demonstrating two genetic pathways to drug abuse. Arch Gen Psychiatry 1995; 52(1): 42-52.

48. Emmerson RY, Dustman RE, Shearer DE, Chamberlain HM. EEG, visually evoked and event related potentials in young abstinent alcoholics. Alcohol. 1987; 4(4): 241-248.
Corresponding author:

Javier Rodríguez-Torresano

Department of Psychiatry

Hospital 12 de Octubre

Avda. de Cordoba s/n

28041, Madrid

Spain

Tel: +34913908022

Fax: +34913908538

E-mail: jrodriguezt.scsm@salud.madrid.org 